\title{
Evaluation of NHS referral of postnatal women to a commercial, community-based lifestyle modification programme
}

\author{
W. L. Wrieden ${ }^{1}$, H. Williams ${ }^{1}$, J. Thompson ${ }^{2}$, G. Mcfarlane ${ }^{2}$, C. Barnett ${ }^{2}$ and Z. Hellman ${ }^{3}$ \\ ${ }^{1}$ Institute for Health and Welfare Research, Robert Gordon University, Schoolhill, Aberdeen, AB10 1FR, UK, \\ ${ }^{2}$ Directorate of Public Health, NHS Tayside, Kings Cross, Clepington Road, Dundee, DD3 8EA and ${ }^{3}$ Weight Watchers (UK) \\ Ltd, Maidenhead, Berkshire, SL6 2SL
}

It is well established that the period following pregnancy and childbirth is a time when women are likely to gain weight. This has significant consequences for further pregnancies as obese women have a higher risk of impaired glucose tolerance and gestational diabetes, miscarriage, pre-eclampsia, thromboembolism and maternal death ${ }^{(1)}$.

Suitable women $(n=547)$ who presented with a BMI above 30 at antenatal booking clinics in the NHS Tayside (Scotland) region were offered access to a commercial, community-based lifestyle weight management programme (Weight Watchers ${ }^{\mathbb{R}}$ ) in the postnatal period. Participants received vouchers to attend 12 weekly community meetings, combined with access to online and mobile tools. Data was collected by group leaders and relayed to a central database (weight measured in meetings on calibrated scales). Analysis was based on 87 referrals that commenced between April and June 2012 and completion was defined as attendance at 9 or more meetings ( $\geqslant 75 \%$ engagement). Intention-to-Treat analysis, Baseline Observation Carried Forward (ITT BOCF) was carried out where those attending 8 or fewer sessions were assumed to have maintained their baseline weight (weight change $=0$ ).

At baseline participants had a median age of 32 years (Inter Quartile Range 29.1-36.7) with a median BMI of $34.4 \mathrm{~kg} / \mathrm{m}^{2}$ (Inter Quartile Range 31.9-39.1). Participants lost an average of 4.84 (SD 4.49) kg, equating to 5.10 (SD 4.79) \% of their initial body weight (ITT BOCF). Of the 87 women who were referred $55(63.2 \%)$ completed 9 or more sessions. A higher proportion of older women (32 or above) completed the course (69.8\% versus $56.8 \%$ respectively) and there was a strong association between the number of meetings attended and weight loss (Pearson correlation coefficient $0.748, P<0.01$ ) and this was reflected in the ITT analysis. Comparison of weight loss in completers showed that older women had a higher mean $\%$ body weight loss than younger participants.

\begin{tabular}{|c|c|c|c|c|c|c|c|c|}
\hline \multirow[b]{2}{*}{ Age group } & \multirow[b]{2}{*}{$n$} & \multicolumn{2}{|c|}{ Weight loss (kg) } & \multicolumn{2}{|c|}{$\%$ body weight loss } & \multicolumn{2}{|c|}{ BMI change $\left(\mathrm{kg} / \mathrm{m}^{2}\right)$} & \multirow{2}{*}{$\begin{array}{c}\geqslant 5 \% \text { body weight loss } \\
n \text { ( } \% \text { of age group) }\end{array}$} \\
\hline & & Mean & SD & Mean & SD & Mean & $\mathrm{SD}$ & \\
\hline \multicolumn{9}{|l|}{ ITT BOCF } \\
\hline$<32$ years & 44 & 3.87 & 4.24 & 3.95 & 4.33 & 1.42 & 1.58 & $19(43)$ \\
\hline$\geqslant 32$ years & 43 & $5.83 *$ & 4.57 & $6.27 *$ & 4.99 & $2.18^{*}$ & 1.70 & $29(67)$ \\
\hline \multicolumn{9}{|l|}{ Completers } \\
\hline$<32$ years & 25 & 6.82 & 3.36 & 6.95 & 3.45 & 2.51 & 1.28 & 19 (76) \\
\hline$\geqslant 32$ years & 30 & 8.35 & 2.92 & $8.99 *$ & 3.29 & 3.12 & 1.07 & $29(97)$ \\
\hline
\end{tabular}

$* p<0.05$ for difference from mean for $<32$ years using student $t$-test comparing age groups.

In conclusion, this community-based lifestyle modification programme may be an appropriate intervention for postnatal weight loss in overweight and obese women.

Funded by Weight Watchers (UK) Ltd.

1. National Institute for Health and Clinical Excellence (2010) Dietary interventions and physical activity interventions for weight management before, during and after pregnancy. http://www.nice.org.uk/nicemedia/live/13056/49926/49926.pdf. 